laic, és a dir, en un Estat on imperi la laïcitat, es respectaran les esglésies, «siempre y cuando no se inmiscuyan en los asuntos que han de ser administrados públicamente» (105); una formulació que caldria precisar car, si es pren al peu de la lletra, implica que aquells que parlen en nom d'una confessió veuen retallada la seva llibertat d'expressió i pateixen un greuge comparatiu. És interessant el que observa Valcárcel sobre la laïcitat: quan les religions se sotmeten als principis de la tolerància, bé sigui per motius doctrinals propis, com és el cas del protestantisme, bé sigui instrumentalment perquè li hagi estat imposada o hagi estat adequat d'adherir-s'hi per defensar-se davant d'una majoria, com és el cas de l'Església Catòlica, no només tendeixen a recloure's a l'espai privat (amb la qual cosa la seva tesi de la privatització de la religió és tant una prescripció normativa - "sería muy bueno que todas, absolutamente todas [las religiones], se volvieran privadas y espirituales» (110) — com la descripció d'un desenvolupament històric objectiu), sinó que també s'espiritualitzen. Aquest segon fet es pot observar en el discurs omnipresent de l'espiritualitat a l'Occident de principis del segle XXI. L'espiritualització de la fe va de la mà de la individualització de la societat. L'individu cerca respostes a la pregunta sobre el sentit de la vida en les tradicions que té a l'abast, i les utilitza de manera selectiva, no tant per salvar-se com per sobreviure a les societats ordenadament alienades de l'Occident mundialitzat.
Dediquen més endavant dues cartes al problema del mal, assumpte suscitat per la creixent presència de fonamentalismes religiosos arreu. Altres qüestions, com la del paper de la dona a la religió o la força socialment cohesionadora de la $\mathrm{fe}$, reben la consideració detallada de les autores. També s'endinsen en la controvertida qüestió de l'ensenyament religiós a les escoles.

Sobre aquest tema les autores sostenen que la religió que s'hi ensenyi no ha de ser catequesi, sinó el coneixement de l'anomenat fet religiós, de la història de les religions que ens aporta sabers imprescindibles per esbrinar qui som i a quina cultura pertanyem. En un altre apartat, Camps es refereix a les ofenses religioses, amb motiu de la publicació de les prou conegudes caricatures daneses de Mahoma, i constata que la immunitat que les religions reclamen i la susceptibilitat exagerada dels religiosos són mostres que la secularització encara no ha reeixit a amarar tota la societat.

Per acabar, val a dir que una de les virtuts d'aquest llibre és el relaxament estilístic propiciat pel gènere epistolar. Les autores, assagistes de renom, aconsegueixen mantenir un alt nivell en els arguments sense sofisticacions innecessàries. Els assumptes són tractats amb ordre, però permetent-s'hi divagacions i canvis sobtats de tema i, cosa lloable, d'opinió, com en una conversa de sobretaula entre persones cultes i ben educades.

\section{Daniel Gamper}

CABré, Rosa; Domingo, Josep M. (a cura de) (2007).

Estudis sobre el positivisme a Catalunya.

Vic: Eumo Editorial. 509 p.

De l'obra que ara ressenyem, sorgida d'un projecte de recerca universitària, en podem dir que s'inscriu dins del moviment de renovació metodològica que s'està produint a molts països europeus $\mathrm{i}$ llatinoamericans, dirigit a interrogar-se altrament sobre les condicions que possibiliten la reconstitució de la tradició prò- 
pia. Aquests estudis adquireixen forma concreta en preguntar-se pels llocs i les formes d'importació i de la «naturalització» dels conceptes que, procedents d'altres tradicions, han ajudat a construir un pensament propi.

Des que Victor Cousin institucionalitzà els «viatges filosòfics» en desplaçarse a Alemanya per buscar una filosofia que substituís la dels ideòlegs, llavors vigent en l'escena francesa, les importacions i naturalitzacions del pensament han estat constants en l'àmbit europeu. L'esmentat projecte que ara veu la llum ha optat per ocupar-se de la reconstrucció de la presència del positivisme a Catalunya mitjançant l'anàlisi d'alguns itineraris particulars, com ho són el de Pere Estasén, Francisco Tubino, Joan Giné i Josep Miquel Guàrdia, elegits en funció del seu caràcter paradigmàtic. $\mathrm{Al}$ costat d'això, l'apreciació del positivisme dins d'un marc ampli en el qual es desenvolupen diverses activitats —l'edició i la traducció de textos, la publicació de revistes, la revisió de la història literària- i un escrit sobre la recepció de Renan completen aquesta extensa obra.

El positivisme a Catalunya, reporten els editors en paraules de Pere Estasén a l'Ateneu Barcelonès l'any 1877, comptà amb la predisposició de la societat catalana d'aquell moment a rebre l'influx de l'obra d'Auguste Comte i dels seus deixebles. El positivisme fou vist com un moviment de renovació capaç de transformar i engrescar les estructures culturals, socials i econòmiques, sense desvincular-se de la tradició. Aquesta és una línea cabdal per entendre l'àmplia influència que el positivisme tingué, enfront d'altres moviments filosòfics. De la mà del positivisme es podia justificar el reformisme polític i els avenços científics que comportaven més benestar i una millora del nivell de vida.

Els projectes editorials de Josep Yxart, àmpliament presentats en el treball, són un clar exponent de la necessitat de dur a terme una política editorial per fer arribar a un públic més ampli moltes de les obres literàries i filosòfiques que en aquell moment es publicaven a França. Els autors han volgut singularitzar aquesta influència de la cultura francesa en la persona d'Ernest Renan, no només per les qüestions ideològiques que es desprenien de la seva obra i que eren moltes, sinó per les diverses maneres d'apropiació que la seva obra tingué entre els intel.lectuals catalans de la fi de segle.

Aquesta concepció del positivisme que ens arribà per obra de Renan es pot copsar resseguint les línies temàtiques desenvolupades per la revista La Renaixensa. Les propostes científiques, la concepció determinista de la història i la proposta artística queden àmpliament reflectides a les pàgines de la revista. Abans, però, que això fos possible, calgué una abundant recepció del moviment positivista, que arribava a Barcelona primer de forma clandestina i després més lliurement, a través de revistes i llibres que es publicaven al país veí. Pompeu Gener explica en les seves Antimemòries que el text de Comte Discurs sobre l'esperit positiu li va ser lliurat per un bijoutier francès que tenia botiga a la plaça Reial. D'aquesta manera i de moltes altres, es van anar abastint les biblioteques barcelonines. És força interessant, especialment de cara a recerques posteriors, el treball de recopilació que es fa en aquest llibre sobre les obres i autors catalogats d'aquell període, és a dir, de l'últim terç del segle XIX.

Seria una visió incompleta del període, encara que pel fet de tractar-se del positivisme a Catalunya pugui semblar paradoxal, silenciar l'existència d'autors que van realitzar la seva obra fora del país. Aquest és un aspecte que sovint s'oblida, però en aquest cas no ha estat així. Es tracta en concret de Josep Miquel Guàrdia, com podia haver-se tractat de Pompeu Gener. Guàrdia no només va dur a terme a París una llarga carrera de for- 
mació filosòfica, sinó que hi va desenvolupar la seva activitat com a professor i pensador. L'obra de Guàrdia, lamentablement quasi absent de les nostres biblioteques, forma part dels fons de la Biblioteca Nacional francesa. I no només això, sinó que els escrits de Guàrdia dedicats a la filosofia política de l'educació són considerats encara avui, juntament amb els de Ferrer, com un model laic alternatiu al jacobí imperant a França des de la Revolució.
No cal dir que seria quimèric per part dels responsables del projecte voler abastar tot el camp que el títol d'aquest treball comporta. Per tant, l'ús genèric que se'n fa s'adiu del tot amb el seu objectiu declarat de voler escampar una mica de llum sobre un camp insuficientment explorat. Un objectiu i un desig, doncs, orientats a manifestar les mancances i a animar altres a continuar la tasca.

Jordi Riba 